\title{
Translocation and introduction of the Zanzibar red colobus monkey: success and failure with an endangered island endemic
}

\author{
Thomas T. Struhsaker and Kirstin S. Siex
}

The Zanzibar red colobus Procolobus kirkii is one of Africa's most endangered primates, with only c. 1500-2000 individuals remaining in the wild. The authors made preliminary surveys of three areas where this monkey was translocated or introduced in the 1970s and 1980s. It appears that only one of these releases was successful. A total of 67 animals were caught and translocated or introduced (including four that died during the process). Thirteen to 20 years later, 62-70 red colobus were located at the three sites; i.e. there had been no net gain in colobus numbers as a result of the translocations and introduction. One attempt apparently failed because of insufficient habitat, and another perhaps because of insufficient numbers of colobus or an imbalance in the age and sex composition of animals released. The one successful translocation involved moving a fairly large number of monkeys (36) into a forest with a relatively high diversity of tree species. In light of these findings, the authors recommend that far more attention be given to protecting the monkeys and their habitat where they currently exist, rather than spend time and money on translocations that are as likely to fail as to succeed.

\section{Introduction}

The Zanzibar red colobus monkey Procolobus kirkii is endemic to the island of Zanzibar (locally referred to as Unguja) and the very small island of Uzi, which is joined to Unguja by a narrow isthmus of tidal mangrove swamp. This species is Endangered (IUCN, 1996), with approximately 1500-2000 individuals remaining in the wild (Struhsaker and Siex, unpubl. reports). None is in captivity and more than half of the wild population lives outside protected areas. The highest concentrations of Zanzibar red colobus live in the Jozani Forest Reserve and in the agricultural areas within 2 $\mathrm{km}$ of the southern end of the reserve. The single most important threat to this species is habitat destruction resulting from the rapidly increasing human population ( $3-4$ per cent per year) and its exponentially increasing demand for agricultural land, firewood, charcoal

(C) $1998 \mathrm{FFI}$, Oryx, 32 (4), 277-284 and building poles. Road-kills by vehicles and hunting are also important, but somewhat less serious, threats to the monkeys (Struhsaker and Siex, 1997).

Zanzibar red colobus are important not only because of their unique characteristics and endangered status, but also because they are a major tourist attraction and economic asset to Zanzibar (Struhsaker and Siex, 1997). Tourism in Zanzibar is rapidly becoming a major source of revenue for the islands. Tourism to Jozani Forest Reserve, mainly to view the Zanzibar red colobus, increased from 6000 visitors in 1995 to 12,000 in 1996, each of whom pay a fee of \$US2.

We conducted demographic and basic ecological studies of this species from 1991 to 1996 (Siex, 1995; Struhsaker et al., 1997; Siex and Struhsaker, unpubl. data). During the course of these studies we made preliminary surveys of two areas where this colobine was 
translocated and one where it was introduced in the 1970s and 1980s. These surveys are important because they provide information on the relative success of translocations and introductions as a conservation tool.

We are not aware of any documented cases of successful translocations or introductions of African forest monkeys within mainland Africa. Olive baboons Papio anubis have been translocated successfully in Kenya (Strum, 1987). In the course of the studies reported here, we have discovered another likely case of a successful primate introduction. This concerns the vervet monkey Cercopithecus aethiops on Unguja Island. Pakenham (1984) did not report this species as being present on Unguja when he worked there in 1938-45. During our studies in 1991-96, we frequently saw vervets in the Masingini forest and less frequently at Kichwele. It appears that this species is beginning to successfully colonize the western part of Unguja, where we speculate that it was accidentally introduced by escaped or released pets. Similar events apparently transpired with the successful naturalization of $C$. aethiops on the islands of Barbados and St Kitts, and C. mona on the islands of Grenada, São Tomé and Príncipe. Cercopithecus aethiops and C. mona, like Papio spp., are considered to be colonizing species that are highly adaptable in terms of habitat use and in surviving hunting pressure from humans. As a consequence, releases of species with these characteristics are more likely to succeed than releases of more highly specialized species, such as those of the genus Procolobus.

Translocation usually, but not always, refers to the capture of free-ranging wild animals in their native habitat and their release into natural or near-natural habitat within their geographical range. The release of captured animals is usually done within a few days of capture. Translocation is distinguished from reintroduction, which refers to the transfer of captive animals (usually captive bred) into the wild. The problems involved with reintroductions were reviewed by Caldecott and Kavanagh (1983) and Beck et al. (1994).

We report here what appear to be one successful and one failed translocation, and one failed introduction of Zanzibar red colobus monkeys. These cases provide some insight into factors that determine the likelihood of a successful translocation or introduction. Translocation and introduction as approaches to conservation are usually considered to be two of the last and relatively desperate options; surpassed only by reintroductions or total reliance on captive populations. It is particularly relevant in situations where rare habitats and/or populations are being destroyed, and where alternative and unoccupied habitat exists. An important contingent is that the translocation or introduction process does not adversely affect plant or animal species in the area into which the animals are being moved. Here we report data only on the translocated and introduced Zanzibar red colobus; we have no data as to the effect these translocations and introduction may have had on other species.

\section{Translocation and introduction sites}

Zanzibar red colobus were translocated to two sites, Masingini and Kichwele Forest Reserves, located on Unguja Island. Historical data on the vegetation of Unguja suggest that red colobus probably occurred naturally in both the Masingini and Kichwele areas prior to their conversion to agriculture in the 1800 s (Pakenham, 1984). Red colobus were introduced to Ngezi Forest Reserve, located on Pemba Island.

The Masingini Forest Reserve is located on a low ridge ( $<110 \mathrm{~m}$ elevation) approximately 2-3 km north-east of Zanzibar town (Figure 1). This area was badly eroded prior to 1953 and, because it constitutes the main water catchment for the town of Zanzibar, land was purchased and a reforestation project was initiated by the Department of Agriculture (including Forestry). The reserve was planted with a wide variety of trees, most of which are not indigenous to Zanzibar. Monotypic stands of Pinus caribaea, Tectona grandis, Eucalyptus tereticornis and Calophyllum inophyllum, as well as small agricultural plots, occur around the rather steep slopes and gullies, and a small 
Figure 1. Unguja island, Zanzibar, Tanzania, East Africa. Note Jozani Forest Reserve and translocation areas: Masingini Forest and Kichwele.

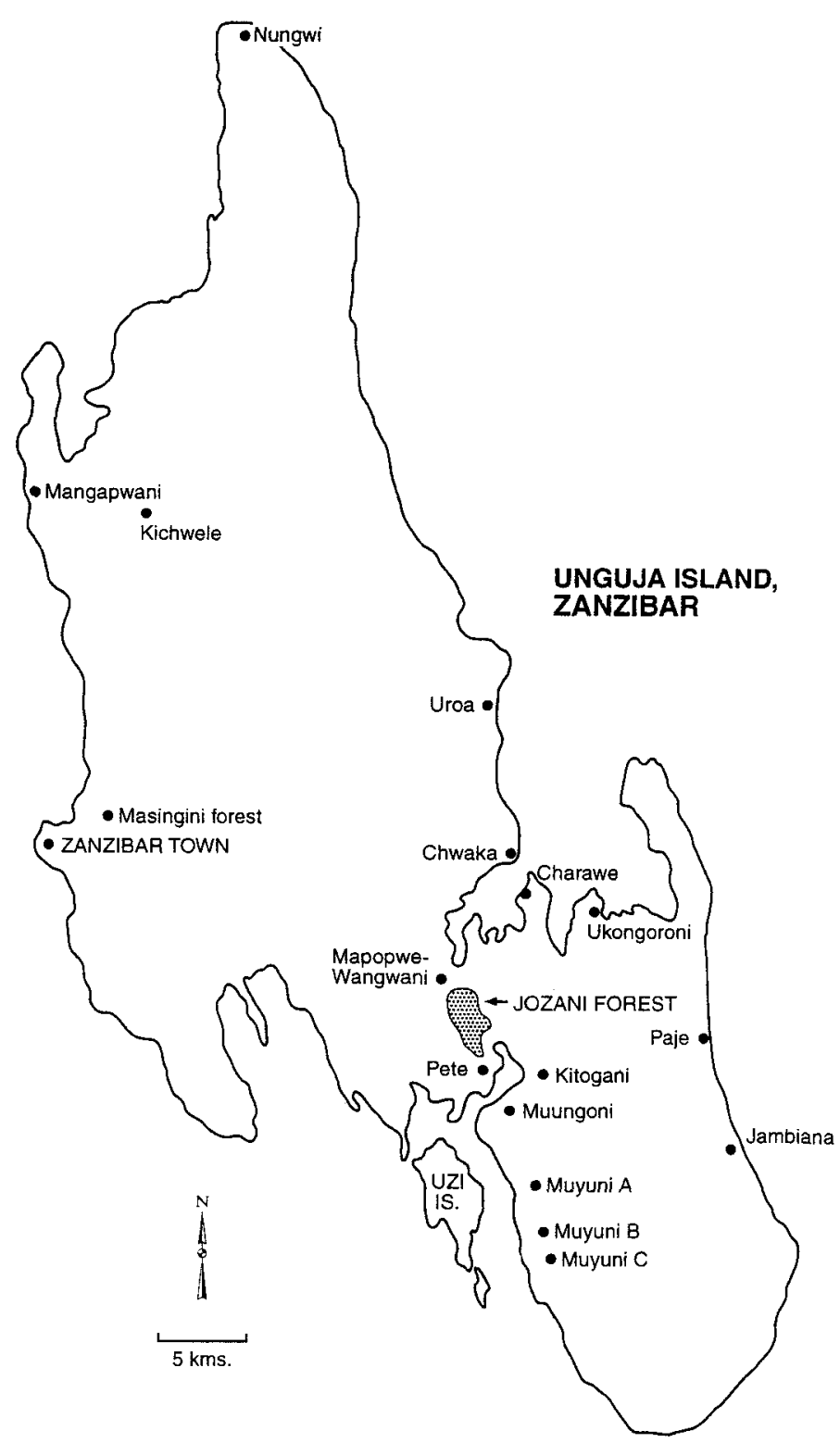

part of the ridge on the western side of the reserve. The largest part of the western ridge is forested with a wide range of tropical hardwoods (indigenous and non-indigenous), including Maesopsis eminii, Swietenia sp., Milicia (Chlorophora) excelsa, Erythrophleum suaveolens, Syzygium (Eugenia) cumini, Eugenia caryophyllus, Harungana madagascariensis, Vitex doniana, Artocarpus heterophyllus, Mangifera indica,
Bridelia micrantha and Parinari curatellifolia. The red colobus translocated to Masingini have been seen only in the mixed-species tropical hardwood forests and not in the monotypic tree plantations. We estimate that the habitat suitable for red colobus in Masingini was about $2 \mathrm{sq} \mathrm{km}$.

Human activities in the Masingini Reserve include harvesting of the trees planted in 
monocultures and a limited amount of cutting in the mixed hardwood forest for building poles and timber. Some hunting may occur, but we suspect this is primarily for duikers (Cephalophus adersi and C. monticola), suni Nesotragus moschatus and bush pigs Potamochoerus porcus, and not for monkeys. However, dogs were once seen chasing vervet monkeys in Masingini.

In addition to the red colobus and vervets, other primates in Masingini include Sykes's monkeys Cercopithecus mitis albogularis and greater bushbabies Otolemur g. garnettii. Red colobus are not known to occur in the agricultural areas surrounding Masingini. This, combined with the fact that the Masingini Forest is largely planted and was primarily a degraded area with serious problems of soil erosion in the 1950s, suggests that no red colobus lived there in recent times prior to the translocations in the 1970s and 1980s.

The Kichwele Forest Reserve (approximately $10 \mathrm{sq} \mathrm{km}$ ) is located $14 \mathrm{~km}$ north-east of Zanzibar town (Figure 1). This reserve is surrounded by cultivation. It is a timber-producing reserve that is dominated by plantations of Eucalyptus sp., with narrow strips of natural hardwood forest along the streams. The area of natural forest appears to cover a total area of $1 \mathrm{sq} \mathrm{km}$ or less. Because Kichwele is a reserve planted to produce wood, clearcut logging of Eucalyptus is the dominant human activity in this area. We have no information on hunting in this reserve.

The only other non-human primate seen in Kichwele was the vervet monkey, but it is likely that the greater bushbaby is also present because it seems to occur in a wide variety of habitats throughout the island.

The Ngezi Forest Reserve (14.4 sq km) is located in the north-western part of Pemba (Figure 2). Beentje (1990) reported that only $5.5 \mathrm{sq} \mathrm{km}$ of this reserve are covered with moist forest, and $2 \mathrm{sq} \mathrm{km}$ with coastal evergreen thicket and dry coastal forest. The remainder is covered with giant heath (Philippia sp.) and secondary bush resulting from overharvesting of the moist forest. Common tree species in the moist forest include: Odyendea zimmermannii, Uapaca guineensis, Antiaris toxi- caria, Elaeis guineensis, Erythrophloeum suaveolens, Pachystela brevipes, Bombax rhodognaphalon and Croton sylvaticus. Maesopsis eminii is an introduced exotic that is colonizing the reserve so successfully as to be considered a pest (Beenjte, 1990).

The reserve was established in the early 1920 s as a production forest reserve. Selective harvesting of timber has occurred there ever since. Replanting with exotics and indigenous species began in the 1940s. In addition to selective logging, trees are cut for building poles and firewood.

\section{Translocations and introduction}

Details of catching methods, holding cages and localities were given in Silkiluwasha (1981). Monkeys were translocated from two locations approximately $0.5 \mathrm{~km}$ south and south-east of Pete (Figure 1). The translocations were done because the area was totally lacking in protection and was subject to clearcutting.

Monkeys were caught by encircling a group's sleeping site with fishing nets early in the morning and then the surrounding undergrowth and some of the trees were cut down. Some people stood near the nets while others climbed the trees and shook the branches to force the moneys to the ground. When the monkeys ran into the nets, they were caught by hand and put into sacks, and from there into cages. Attempts were made to catch as many group members as possible, but generally only about one-third of a group was caught. The monkeys were usually driven by vehicle to the release site and released on the same day of capture. In one exceptional case, nine colobus were kept in cages for 2 months prior to release. These nine were fed on fresh leaves of Terminalia catappa. No deaths occurred in the captive monkeys (Silkiluwasha, 1981).

\section{Masingini}

Four releases were made into the Masingini Forest Reserve. Silkiluwasha (1981) reported 


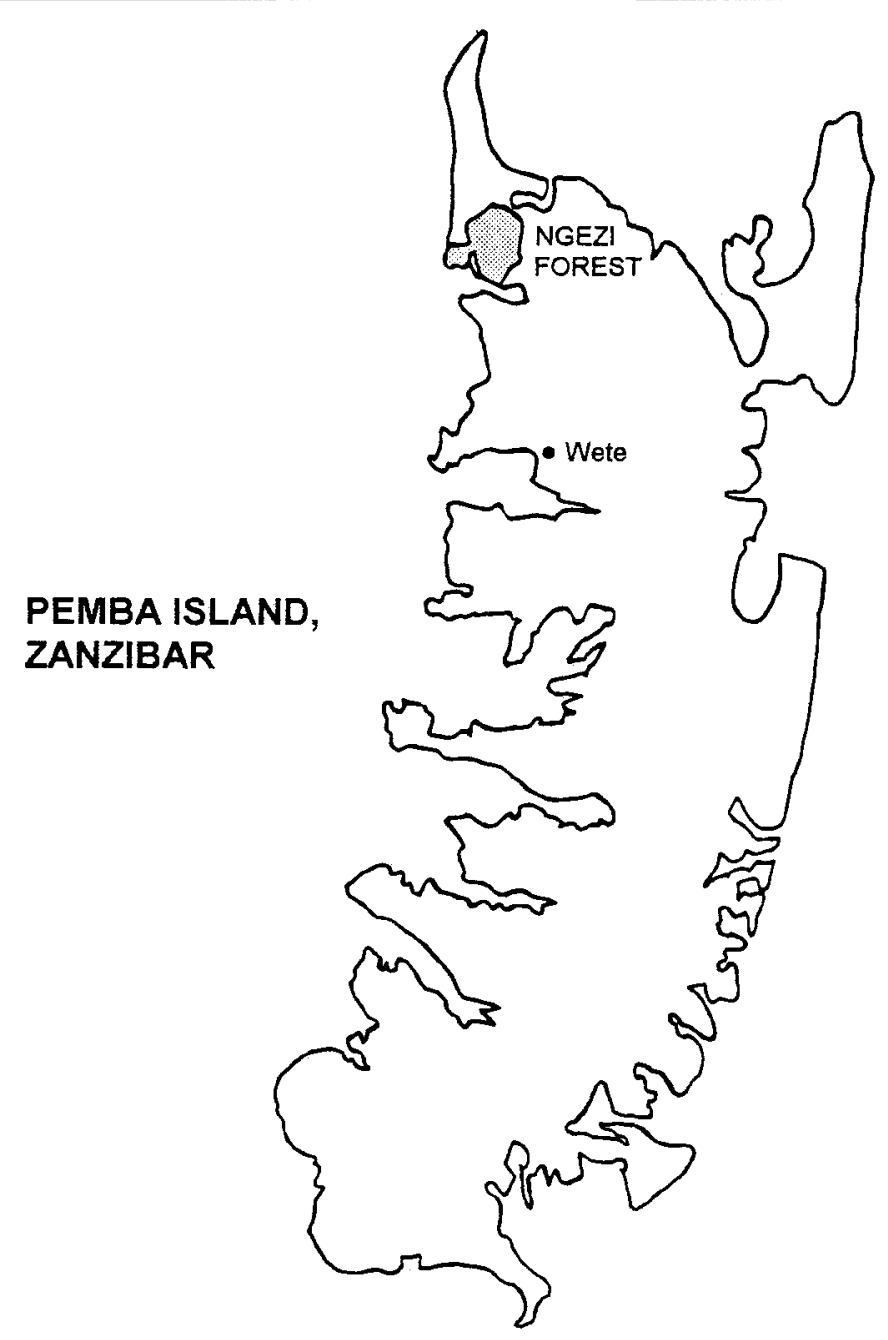

Figure 2. Pemba Island,

Zanzibar, Tanzania, East Africa. Note introduction area of Ngezi Forest.

PEMBA ISLAND, ZANZIBAR

that 23 colobus were translocated there in three moves (January 1977, October 1978 and November 1978). These comprised three adult males, three subadult males, ten adult females, two subadult females, two infant males and three infant females. In addition, two adult females died in the translocation process (8 per cent mortality). No deaths or births occurred during the first year or two after the release (Silkiluwasha, 1981).

Zanzibar Forest Department records report that a fourth release into Masingini was made 
on 18 February 1981. This consisted of 13 colobus ( 10 females and three males of mixed ages). No further details were given, although it is possible that some of these monkeys were taken from the Jozani Forest Reserve. This brings the total of red colobus released into Masingini to at least 36 individuals with a sex ratio of 2.8 females per male. The four releases occurred over a period of nearly 50 months.

\section{Kichwele}

Thirteen red colobus were translocated to the Kichwele Forest Reserve during one move in December 1978. These comprised two adult males, five adult females, three subadult females, one infant male and two infant females. In addition, one adult female and one juvenile male died during capture and/or translocation (Silkiluwasha, 1981), giving a mortality rate of 13.3 per cent.

\section{Ngezi, Pemba}

We have no written documentation on the number of red colobus that were introduced to the Ngezi Forest Reserve on the island of Pemba. In 1991, one of us (T.T.S.) was told by a forest guard, Toufiki Juma, that 14 red colobus were introduced there in 1974. Red colobus do not occur naturally on Pemba.

\section{Survey methods}

We surveyed the red colobus in Masingini during 8 partial days: one in 1991, three in 1994, three in 1995 and one in 1996. The most reliable counts of red colobus groups were made in 1994. In this set of surveys, as well as those at Kichwele and Ngezi, we attempted to cover as much of the forest as possible, paying particular attention to those habitats most likely to contain colobus. We used pre-existing trails as census routes. Once a colobus group was encountered, we attempted to make a complete count of it.

One of us (T.T.S.) spent 2 half-days surveying the small Kichwele Forest Reserve in 1991 and 1996. In addition, Hamza Z. Rijal of the
Zanzibar Department of the Environment spent 2 days searching for red colobus in Kichwele in 1991.

T.T.S. spent 4 hours searching the Ngezi Forest Reserve in 1991 and Hamza Z. Rijal spent 18 days there in 1992.

\section{Results}

Three red colobus groups were encountered at Masingini, totalling 56-64 individuals (Table 1). Seventeen ( 30.4 per cent) of these monkeys were infants and juveniles, indicating reasonable reproduction and recruitment. The combined adult/subadult sex ratio (two females per male) appears not to have changed since the translocation.

We believe that our count of 56-64 individuals represents a close approximation of the total number of colobus in Masingini because the reserve is small and is circumscribed by unsuitable habitat. Red colobus were seen only in the mixed hardwood forest. This count represents an increase of 55.6-77.8 per cent (36 vs 56-64) during a period of c. 13-17 years (1977-1981 to 1994). These results suggest that, on average, the population at Masingini increased at roughly 4.4 per cent per year. The translocation would appear to be a success.

No red colobus were heard or seen during two visits to Kichwele (T.T.S.). Hamza Z. Rijal informed us that he failed to see any red colobus there during 2 days of surveying this area in 1991, although he believes he heard a red colobus twice during this survey. These results, combined with the very small area of habitat suitable for red colobus at Kichwele, leads us to conclude that few, if any, red colobus survived the translocation or produced offspring that survived. We conclude that the translocation to Kichwele was a failure.

During a 4-hour survey of the Ngezi Forest Reserve by T.T.S., no red colobus were heard or seen, although seven groups and two solitary vervets were encountered. Hamza $Z$. Rijal reported to us that he saw only six red colobus at Ngezi during 18 days of survey in 1992. All were adults. It would appear that the 


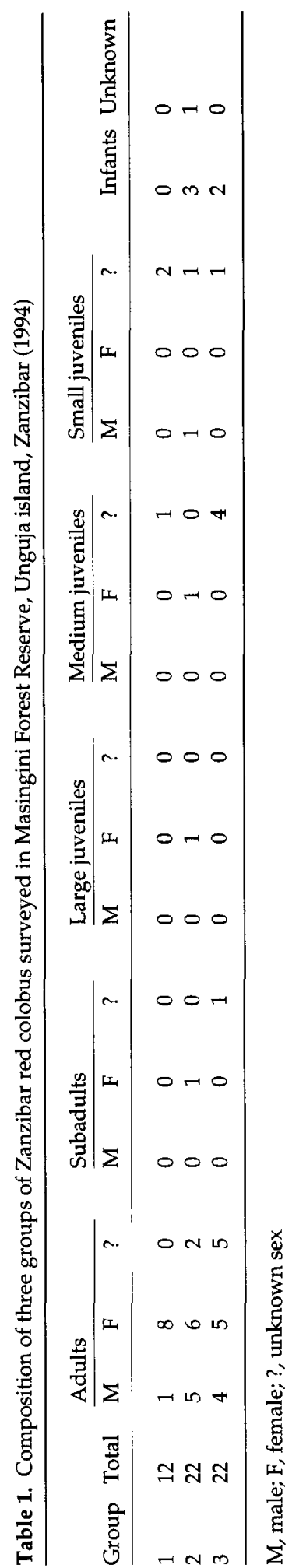

introduction attempt at Ngezi failed to establish a viable population.

Although a small and apparently healthy population of red colobus has been established at Masingini as a result of the translocation, this is countered by the apparent failures at Kichwele and Ngezi. A total of 67 animals were caught and translocated/introduced (including four that died during the process); 13-20 years later only $62-70$ red colobus could be located at the three sites. Even if a few more still exist at Kichwele, this does not change the overall result. There was little, if any, net gain in the numbers of red colobus.

\section{Conclusions and recommendations}

It appears that only one of three translocation/introduction projects succeeded with the Zanzibar red colobus. There was no apparent net gain in colobus numbers as a result of these releases. We do not know, however, what would have happened to the colobus had they not been translocated because so much of their natural habitat is being destroyed. Options for future translocations are not apparent because colobus occupy all habitat that appears suitable on Unguja.

It is difficult to be precise about factors that may have led to the success or failure of the release efforts because of inadequate details of the actual translocations and introduction, and because of lack of follow-up information. It appears that the Kichwele attempt failed because of insufficient habitat. Eucalyptus plantations are not adequate for red colobus. Ngezi, however, has a high diversity of tree species and sufficient habitat that appears suitable for red colobus. One can only suggest that the introduction to Ngezi failed because of insufficient numbers of colobus (presumably 14), or some imbalance in the age and sex composition of the intoduced animals. Alternatively, the monkeys may have been killed by people, but this seems unlikely because Pemba is predominately Muslim (Muslims generally do not eat monkeys) and red colobus living in forests do not typically raid crops. The success at Masingini may be 
the consequence of several factors, including a fairly large number of monkeys translocated (36) and a forest with a relatively high diversity of tree species. Area alone does not explain its success because the area of mixed hardwood forest at Masingini is only about 14 per cent the size of Ngezi.

There is very little suitable habitat remaining anywhere on Zanzibar or Pemba for red colobus. All suitable and protected habitats already contain populations of red colobus. Consequently, we recommend that far more attention be given to protecting the monkeys and their habitat where they currently exist rather than spending time and money on translocations that are as likely to fail as to succeed. The translocated population at Masingini should be closely monitored. Monthly counts would be ideal, but censuses should be made at least 3-4 times a year. Obtaining details on the demographic trends of this population are important to understanding its long-term fate and the carrying capacity at Masingini. Genetic studies of inbreeding and drift in this isolated population would also be of great value to understanding its future. We do not recommend translocating any more colobus to Masingini at this time because of the very small area of suitable habitat.

Although it seems unlikely that viable populations of red colobus survive in Kichwele and Ngezi, our samples of these areas are clearly minimal. Two weeks at each of these sites by qualified observers should be sufficient to determine if these areas contain viable populations of red colobus.

Translocations are a last option for conserving an endangered species and ensuring their success is difficult. Protection of existing populations and habitat is typically a more cost-effective approach that has greater chances of success.

\section{Acknowledgements}

We thank the following institutions and individuals for their assistance and co-operation in this project: Zanzibar Sub-Commission for Forestry, Zanzibar Research Council, Zanzibar Department of the Environment, National Geographic Society,
FinnIDA, CARE Austria, Primate Conservation Inc., Sigma XI (Duke University Chapter), Pereira Silima, Hilal Juma, Yussuf Kombo, Thabit Masoud, Amour Bakari Omar, Hamza Z. Rijal, Tony Archer, Toufiki Juma, Timo Vihola, LeRoy Duvall, Anna-Liisa Raunio, Merja Makela, Robert Bensted-Smith, Pippa Heylings, Rob Wild, and Andrew and Becky Browning.

\section{References}

Beck, B.B., Rapaport, L.G. and Stanley Price, M.R. 1994. Reintroductions of captive-born animals. In Creative Conservation: Interactive Management of Wild and Captive Animals (eds P. J. S. Olney, G. M. Mace and A.T.C Feistner), pp. 265-286. Chapman \& Hall, London.

Beentie, H.J. 1990. A reconnaissance survey of Zanzibar forests and coastal thicket. Zanzibar Environmental Studies Series. Number 7 . Commission for Lands and Environment, Zanzibar.

Caldecott, J. and Kavanagh, M. 1983. Can translocation help wild primates? Oryx, 17 (3), 135-139.

IUCN. 1996. African Primates. Status Survey and Conservation Action Plan. Revised Edition. IUCN, Gland, Switzerland.

Pakenham, R.H.W. 1984. The mammals of Zanzibar and Pemba islands. Unpublished report. (In Zanzibar Department of Environment library.)

Siex, K.S. 1995. The Zanzibar red colobus monkey (Procolobus kirkii): ecology, demography and use of Cocos nucifera. MSc thesis, University of Florida.

Silkiluwasha, F. 1981. The distribution and conservation status of the Zanzibar red colobus. African Journal of Ecology, 19, 187-194.

Struhsaker, T.T., Cooney, D.O. and Siex, K.S. 1997. Charcoal consumption by Zanzibar red colobus monkeys: its ecological and demographic consequences. International Journal of Primatology, 18 (1), 61-72.

Struhsaker, T.T. and Siex, K.S. 1997. The Zanzibar red colobus monkey: conservation status of an endangered island endemic. African Primates, Newsletter of the African Section of the IUCN/SSC Primate Specialist Group. 2 (2).

Strum, S. 1987. Translocation of three troups of baboons in Kenya: an update. International Journal of Primatology, 8, 426.

Thomas T. Struhsaker and Kirstin S. Siex, Department of Biological Anthropology, Duke University, PO Box 90383 Durham, NC 27708-0383, USA. E-mail: tomstru@acpub.duke.edu

Received 26 August 1997

Accepted 31 March 1998 